\title{
The oncofetal protein glypican-3 is a novel marker of hepatic progenitor/oval cells
}

\author{
Petar N Grozdanov, Mladen I Yovchev and Mariana D Dabeva \\ Department of Medicine, Marion Bessin Liver Research Center, Albert Einstein College of Medicine, \\ Bronx, NY, USA
}

\begin{abstract}
Glypican-3 (Gpc3), a cell surface-linked heparan sulfate proteoglycan is highly expressed during embryogenesis and is involved in organogenesis. Its exact biological function remains unknown. We have studied the expression of Gpc3 in fetal and adult liver, in liver injury models of activation of liver progenitor cells: D-galactosamine and 2-acetylaminofluorene (2-AAF) administration followed by partial hepatectomy (PH) (2-AAF/PH); and in the Solt-Farber carcinogenic model: by initiation with a single dose of diethylnitrosamine and promotion with 2-AAF followed by PH treatment. Gpc3 expression was studied using complementary DNA microarrays, reverse transcriptase-polymerase chain reaction, in situ hybridization (ISH); ISH combined with immunohistochemistry (IHC) and immunofluorescent microscopy. We found that Gpc3 is highly expressed in fetal hepatoblasts from embryonic days 13 through 16 and its expression gradually decreases towards birth. Dual ISH with Gpc3 and $\alpha$-fetoprotein (AFP) probes confirmed that only hepatoblasts and no other fetal liver cells express Gpc3. At 3 weeks after birth the expression of Gpc3 mRNA and protein was hardly detected in the liver. Gpc3 expression was highly induced in oval cell of D-gal and 2-AAF/PH treated animals. Dual ISH/IHC with Gpc3 riboprobe and cytokeratin-19 (CK-19) antibody revealed that Gpc3 is expressed in activated liver progenitor cells. ISH for Gpc3 and AFP performed on serial liver sections also showed coexpression of the twooncofetal proteins. FACS isolated oval cells with anti-rat Thy1 revealed expression of Gpc3. Gpc3 expression persists in atypical duct-like structures and liver lesions of animals subjected to the Solt-Farber model of initiation and promotion of liver cancer expressing CK-19. In this work we report for the first time that the oncofetal protein Gpc3 is a marker of hepatic progenitor cells and of early liver lesions. Our findings show further that hepatic progenitor/oval cells are the target for malignant transformation in the Solt-Farber model of hepatic carcinogenesis.
\end{abstract}

Laboratory Investigation (2006) 86, 1272-1284. doi:10.1038/labinvest.3700479; published online 2 October 2006

Keywords: Gpc3; Gpc3 expression; hepatic progenitor cells; oncofetal protein; oval cell marker

Hepatic progenitor/oval cells proliferate in the liver after acute or chronic injury when the regenerative capacities of hepatocytes are compromised. ${ }^{1}$ These cells, the progeny of putative stem cells, behave like bipotential progenitor cells capable of differentiation into mature hepatocytes and biliary epithelial cells, recapitulating hepatoblast differentiation during fetal development. ${ }^{2-4}$ There is increasing evidence that hepatic progenitor/oval cells can undergo malignant transformation and give rise to hepatocellular carcinoma and cholangiocarcinomas (see Sell ${ }^{5}$ and Roskams et $a l^{6}$ ).

Correspondence: Dr MD Dabeva, MD, PhD, Department of Medicine, Marion Bessin Liver Research Center, Albert Einstein College of Medicine, 1300 Morris Park Avenue, Bronx, NY 10461, USA.

E-mail: Dabeva@aecom.yu.edu

Received 8 May 2006; revised 23 August 2006; accepted 27 August 2006; published online 2 October 2006
Glypicans are heparan sulfate proteoglycans that are attached at their C-terminus to the exocytoplasmic surface of the cell membrane by a glycosylphosphatidylinositol anchor and carry a glycosaminoglycan inserted close to the site of attachment. ${ }^{7,8}$ Six glypicans are identified in mammals and two of them, glypican- 4 and -6 , are expressed in adult liver, shown by Northern blot analysis of total liver RNA. $^{9,10}$ The expression of glypicans is developmentally regulated during embryogenesis, manifesting a specific spatial and temporal pattern. The third member of this family, glypican-3 (Gpc3), is an Xlinked gene with a core protein of approximately $69 \mathrm{kDa} .{ }^{11}$ Mutations in the human GPC3 gene cause Simpson-Golabi-Behmel syndrome, associated with pre- and postnatal tissue overgrowth, increased risk of embryonic tumors during early childhood, and numerous visceral and skeletal anomalies. ${ }^{12}$ Gpc3deficient mice exhibit the specific characteristics described in Simpson-Golabi-Behmel syndrome patients: developmental overgrowth, perinatal 
death, cystic and dysplastic kidneys and abnormal lung development. ${ }^{13,14}$ These studies showed that Gpc3 participates in regulation of cell proliferation and apoptosis during morphogenesis. It was found that Gpc3 is highly expressed in the mouse embryo, especially in mesoderm-derived tissues. In the endoderm, the transcripts were observed on $8.5 \mathrm{dpc}$ and in the liver from 13.5 until $18.5 \mathrm{dpc}$ but not in adult liver. ${ }^{15}$ It was also reported that Gpc3 modulates growth factor signaling during morphogenesis and that this effect is elicited by binding of fibroblast growth factor-2, bone morphogenetic protein (BMP)-4, BMP-7 and WNT to the heparan sulfate side chains of the core protein. ${ }^{14,16-18}$

It was found that Gpc3 is expressed in hepatocellular carcinomas. ${ }^{19-24}$ In cancer cells, the mature form of $\mathrm{Gpc} 3$ is processed releasing the NH2truncated protein of $40 \mathrm{kDa}$ into the medium. The soluble form of Gpc3 was also identified in the serum of patients with hepatocellular carcinomas, ${ }^{22-24}$ which can be used as a serological test for the diagnosis of hepatocellular carcinomas (see Yamauchi et al, ${ }^{24}$ Filmus and Capurro ${ }^{25}$ ).

Studying the gene expression profile of liver epithelial progenitor cells using complementary DNA (cDNA) microarrays, we found that Gpc3 mRNA is overexpressed in rat fetal hepatoblasts and downregulated in adult hepatocytes. We found further that $\mathrm{Gpc} 3$ is differentially expressed in progenitor/oval cells that proliferate in different models of liver injury. Gpc3 expression persists in oval cells and in liver lesions that develop in animals subjected to a carcinogenic regimen. A preliminary report of this work was presented at the Annual Meeting of ISSCR. ${ }^{26}$

\section{Materials and methods}

\section{Animals, Plasmids and Reagents}

Sprague-Dawley male (180 g body weight) and pregnant female rats at $13,14,15,16,17,18$ and 21 embryonic day were purchased from Taconic Farms (German Town, NY, USA). All studies with animals were conducted under the protocol approved by the Animal Care Institute of the Albert Einstein College of Medicine.

Rat specific Gpc3 probe was generated by cloning of a $289 \mathrm{bp}$ long RT-PCR product in pCR4TOPO (Invitrogen, Carlsbad, CA, USA); pBAF 800, which contains $800 \mathrm{bp}$ from $\alpha$-fetoprotein (AFP) messenger RNA (mRNA), was used as described, previously. ${ }^{27}$

2-Acetylaminofluorene (2-AAF) pellets $(35 \mathrm{mg} /$ tablet; 14 days release period) were purchased from Innovative Research of America (Sarasota, FL, USA). All other materials and reagents were purchased either from Sigma-Aldrich (St Louis, MO, USA) or Fisher Scientific (Pittsburgh, PA, USA), unless otherwise noted.

\section{Antibodies}

For immunofluorescent (IF) analysis anti-human Gpc3 antibody (cat num AF2119) prepared in sheep and recognizing the whole molecule was purchased from R\&D Systems (Minneapolis, MN, USA) and used at dilution 1:50. Anti-bovine glial fibrillary acidic protein antibody (GFAP) (cat num G560A) prepared in rabbits was purchased from Promega (Madison, WI, USA) and used at dilution 1:200. Anti-human cytokeratin-19 (CK19) monoclonal antibody (cat num NCL-CK19) was from Novocastra (Newcastle upon Tyne, UK) and used at dilution 1:100. Polyclonal anti-desmin antibody (cat num 29593) prepared in rabbit was from AnaSpec Inc. (San Jose, CA, USA) and used at dilution 1:200. Rabbit polyclonal anti-rat laminin (cat num $\mathrm{Z}$ 0097) was purchased from Dako North America, Inc. (Carpinteria, CA, USA). Monoclonal OV6 antibody was a generous gift from Dr S Sell. Rabbit polyclonal anti-human protein disulfide isomerase (PDI) was a generous gift from Dr R Stockert. All secondary antibodies for IF microscopy prepared in donkeys were purchased from Jackson Immunoresearch Laboratories (West Grove, PA, USA) and used at dilution 1:100.

For cell sorting monoclonal anti-rat CD45 PE (cat num CL009PE) and anti-rat Thy1 (CD90) FITC (cat num CL005F) were purchased from Cedarlane (Burlington, NC, USA) and used at dilution 1:50. For magnetic beads sorting polyclonal rabbit antihuman platelet-derived growth factor receptor beta (PDGFR- $\beta$ ) (cat num PC17) was purchased from Calbiochem (San Diego, CA, USA) and used at dilution 1:10 for stellate cells isolation. Anti-rabbit IgG microbeads were purchased from Miltenyi Biotec (Auburn, CA, USA).

\section{Liver Injury Models}

Two models for activation and proliferation of oval cells were used in this work: 2-AAF treatment in combination with partial hepatectomy (PH) (2-AAF/ $\mathrm{PH}$ ) and D-galactosamine (D-gal) induced liver injury described previously. ${ }^{28} 2$-AAF pellets were implanted subcutaneously and 7 days later PH was performed. The animals were killed and the livers taken on day 2 , 4, 6, 8, 10, 12, 14, 16, 20 and 30 after PH. D-Gal was injected intraperitoneally at a dose of $100 \mathrm{mg} / 100 \mathrm{~g}$ body weight and the livers taken on day 1, 2, 3, 5 and 10 after injury. Five animals were subjected to the Solt-Farber carcinogenic (SFC) protocol for inducing hyperplastic liver lesions. ${ }^{29}$ Diethylnitrosamine was injected intraperitoneally at a dose of $2 \mathrm{mg} / 100 \mathrm{~g}$ body weight. After 2 weeks, two 2-AAF pellets were implanted subcutaneously and after another week $\mathrm{PH}$ was performed. Livers from these animals were collected 2, 5 and 9 months after $\mathrm{PH}$.

\section{Isolation of Hepatoblasts and Nonparenchymal Cells}

Cell suspensions from rat fetal liver were prepared as reported previously. ${ }^{30}$ The cells were plated on 
gelatin-coated dishes at a density of $20 \times 10^{6}$ cells per $10-\mathrm{cm}$ plate and were allowed to attach for $16 \mathrm{~h}$, unattached cells were removed by washing with phosphate buffer saline (PBS).

Nonparenchymal liver cells (NPC) were isolated from D-gal and 2-AAF/PH-treated animals. Livers were taken on day 5 after D-gal treatment and day 10 after the surgery in 2-AAF/PH protocol. Livers at this time point showed the highest number of transit amplifying progenitor cells. Cell fractionation was performed as described previously ${ }^{31}$ with some modifications. Rat livers were perfused with EGTA, followed by collagenase type I (Worthington Biochemical Corp., Freehold, NJ, USA). The livers were excised, minced and suspended in modified Hanks' balanced salt solution (HBSS). Cell suspension was filtered through $80-\mu \mathrm{m}$ nylon mesh, centrifuged for $2 \mathrm{~min}$ at $50 \mathrm{~g}$ in the cold and the pellet (parenchymal fraction) was discarded. The supernatant containing the NPC was centrifuged for $10 \mathrm{~min}$ at $300 \mathrm{~g}$ in the cold. The NPC were suspended in HBSS containing $0.1 \%$ collagenase type I and $0.004 \%$ DNAseI (Roche Applied Science, Indianapolis, IN, USA) and incubated for $30 \mathrm{~min}$ at $37^{\circ} \mathrm{C}$ with shaking. The reaction was stopped by adding fetal bovine serum (FBS) to $10 \%$ final concentration. The cell suspension was filtered consequentially through $45-$ and $30-\mu \mathrm{m}$ nylon mesh, centrifuged for $10 \mathrm{~min}$ at $300 \mathrm{~g}$ and washed several times. Finally, the NPC were equilibrated with OptiPrep (Accurate Chemicals \& Scientific, Westbury, NY, USA) $11 \%$ final concentration and overlaid on top of $14 \%$ OptiPrep. Cells localized between 11-14\% were collected and washed in HBSS, containing 5\% FBS and $20 \mathrm{mM}$ $N$-2-hydroxyethylpiperazine- $N^{\prime}$-2-ethanesulfonic (HEPES), pH 7.4 (Sorting buffer).

Stable oval cell line was established from D-galtreated animal on day 5 after injury. The NPC fraction was obtained as described previously ${ }^{31}$ and after digestion with collagenase, pronase and DNAseI the cells were washed several times with Dulbecco's modified eagle medium containing $25 \mathrm{mM}$ HEPES, $\mathrm{pH}$ 7.4, mixed with equal volume of $50 \%$ Percoll and centrifuged for $30 \mathrm{~min}$ at $800 \mathrm{~g}$. The pellet was washed and the cells seeded sparsely: $1 \times 10^{5}$ cells per $10-\mathrm{cm}$ dish in Dulbecco's modified eagle medium supplemented with $10 \%$ FBS. After a week the oval cells formed multiple colonies with epithelial appearance that were purified by cloning rings.

\section{Sorting of Thy1 Positive/CD45-Negative Progenitor/ Oval Cells and PDGFR- $\beta$ Positive Stellate Cells}

NPC $\left(60 \times 10^{6}\right)$ isolated as described above were labeled with monoclonal anti-CD45 PE conjugated antibody and monoclonal anti-Thy1 FITC conjugated antibody (both diluted 1:50 in sorting buffer) for $30 \mathrm{~min}$ in the cold. Appropriate controls for setting the sorting gates with the two fluorophores were run simultaneously. Sorting of the Thy1
positive/CD45 negative cells were carried out on a MoFlo high speed cell sorter (Dako North America). Viable cells were discriminated and sorted from death cells using To-Pro-3 DNA staining dye (Invitrogen). Cell viability was $75 \%$.

PDGFR- $\beta$ positive stellate cells were isolated after labeling with polyclonal anti-human PDGFR- $\beta$ antibody in sorting buffer. The cells were incubated for 20 min, washed twice with sorting buffer and antirabbit IgG microbeads for MACS (Miltenyi Biotec) were added and the positive cells were collected using a MidiMACS separation unit (Miltenyi Biotec). RNA from Thy1 and PDGFR- $\beta$ positive cells was isolated.

\section{RNA Isolation and cDNA Microarrays}

Total RNA was isolated from frozen liver tissues at the different time points with Trizol reagent (Invitrogen, Carlsbad, CA, USA) as described previously. ${ }^{30}$ RNA for cDNA microarrays was isolated first with Trizol, and then additionally purified with RNeasy Mini Kit (Qiagen Inc., Valencia, CA, USA). RNA integrity was checked on an Agilent 2100 Bioanalyzer. The cDNA microarray labeling reactions were carried out with $100 \mu \mathrm{g}$ total RNA by synthesizing first-strand cDNA using a standard protocol $^{30}$ (http://microarray1k.aecom.yu.edu/). Target and reference cDNAs were labeled with Cy5 and Cy3, respectively. cDNA microarrays were obtained from the Functional Genomics Facility, Albert Einstein College of Medicine). The mouse gene chips contained 8976 clones originally obtained from Incyte Genomics (MGEM V1.0 sequence verified set). The array platform is deposited in the Gene Expression Omnibus (GEO) data repository and can be viewed or downloaded under accession number GPL409.

\section{Reverse Transcriptase-Polymerase Chain Reaction (RT-PCR) Analysis and RNA Probes}

All reverse transcriptase reactions were carried out with SuperScript II Reverse Transcriptase (Invitrogen), according to the manufacturer's protocol. Rat specific primers for different genes were chosen with the Primer3 program. The expression level of glyceraldehyde 3-phosphate dehydrogenase (GAPDH) was used in all cases as an internal control. Sequences of rat-specific primers were as follows: AFP (accession number (acc \#) BC097344) For. 5'GCTGAACCCAGAGTACTGCAC-3', Rev. 5'-GACACG TCGTAGATGAACGTG-3'; CD45 (acc \# Y00065) For. 5'-GTGTTCAGCCAGCTGATCC-3', Rev. 5'-CAGATTC CACGGACCACTG-3'; CK-19 (acc \# AY464140) For. 5'-GGTCAGTGTGGAGGTGGAT-3', Rev. 5'-CTGTTGTA GTGGGCTTCCTG-3'; Desmin (acc \# NM_022531) For. 5'-ATGTCCAAGCCAGACCTCAC-3', Rev. 5'-AGG CCATCTTCACATTGAGC-3'; GAPDH (acc \# NM 017008) For. $5^{\prime}$-AAGGTCATCCCAGAGCTGAA- $3^{\prime}$, 
Rev. 5'-GAGGGCCTCTCTCTTGCTCT-3'; Gpc3 (acc \# NM_012774) For. 5'-ACACCAATGCCATGTTCAAG-3', Rev. 5'-GTGAGCATACGGCCACAGT-3'; Gpc3 probe For. 5'-CCTGGATGAGGAAGGACTTG-3', Rev. 5'-AGC GCAGTTGGTTCTTCACT-3'; Thy1 (acc \# NM_012673) For. 5'-AGCTATTGGCACCATGAAC-3', Rev 5'-CTT ATGCCACCACACTTGA-3'

\section{IF Microscopy}

Frozen rat liver sections $(5 \mu \mathrm{m})$ were fixed in $4 \%$ paraformaldehyde in PBS for $10 \mathrm{~min}$ at room temperature, permeabilized with $0.3 \%$ Triton X100 , treated with sodium borohydride and blocked with 5\% donkey serum, $1 \%$ bovine serum albumin (BSA). The primary anti-human Gpc3 antibodies were applied overnight at $4{ }^{\circ} \mathrm{C}$ in $2 \%$ donkey serum, $1 \% \mathrm{BSA}$ and the secondary, fluorescent conjugated antibody for $40 \mathrm{~min}$ at room temperature. Double labeling experiments were carried out under regular blocking conditions. Sections were counterstained with 4',6-diamidino-2-phenylindole (DAPI). Fluorescent images were taken with a Nikon Eclipse TE 2000-S fluorescent microscope or Leica AOBS confocal microscope.

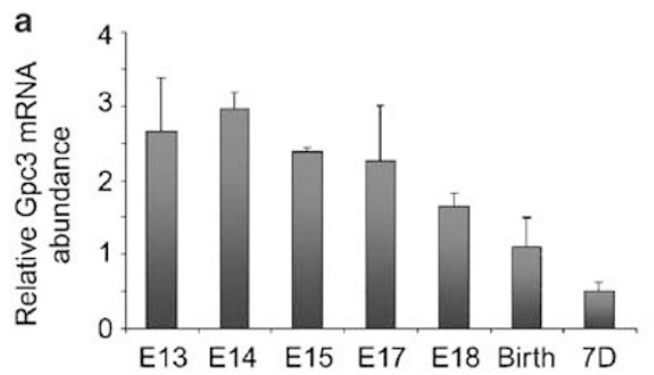

c Isolated fetal liver cells

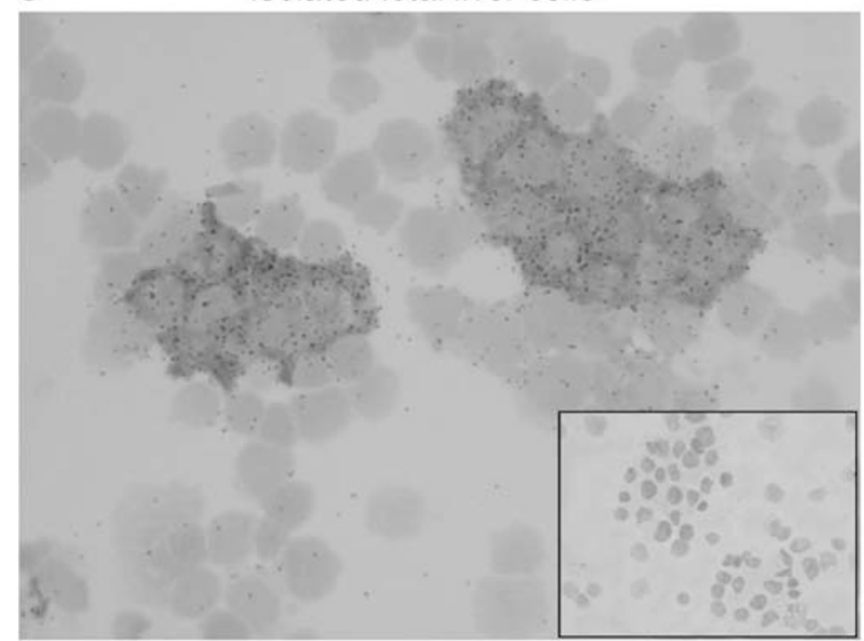

\section{Dual In Situ Hybridization and Immunohistochemistry/In Situ Hybridization Labeling}

Dual in situ hybridization (ISH) and immunohistochemistry (IHC)/ISH were performed, as described previously. ${ }^{27}$ Gpc3 riboprobe was labeled either with ${ }^{35} \mathrm{~S}$ or with digoxigenin; AFP riboprobe was labeled with digoxigenin. For detection of the radioactive hybrids, the slides were embedded into autographic emulsion (NBT2; Kodak, Rochester, NY, USA) and exposed for 2-4 weeks. Digoxigenin labeled hybrids were detected with anti-digoxigenin-AP and antidigoxigenin-POD antibodies (Roche Applied Science). Alkaline phosphatase activity was visualized with BCIP/NBT (Roche Applied Science) and peroxidase activity was visualized with 3,3-diaminobenzidine.

For double IHC/ISH, frozen slides were first processed with CK-19 antibody and peroxidase activity from secondary anti-mouse antibody was visualized by 3,3-diaminobenzidine staining, and then ISH was performed with ${ }^{35}$ S-labeled Gpc3 antisense riboprobe. Slides were exposed with autographic emulsion for 2-4 weeks. All slides were weakly stained with hematoxylin and eosin (H\&E). Pictures were taken with a Nikon coolscope.
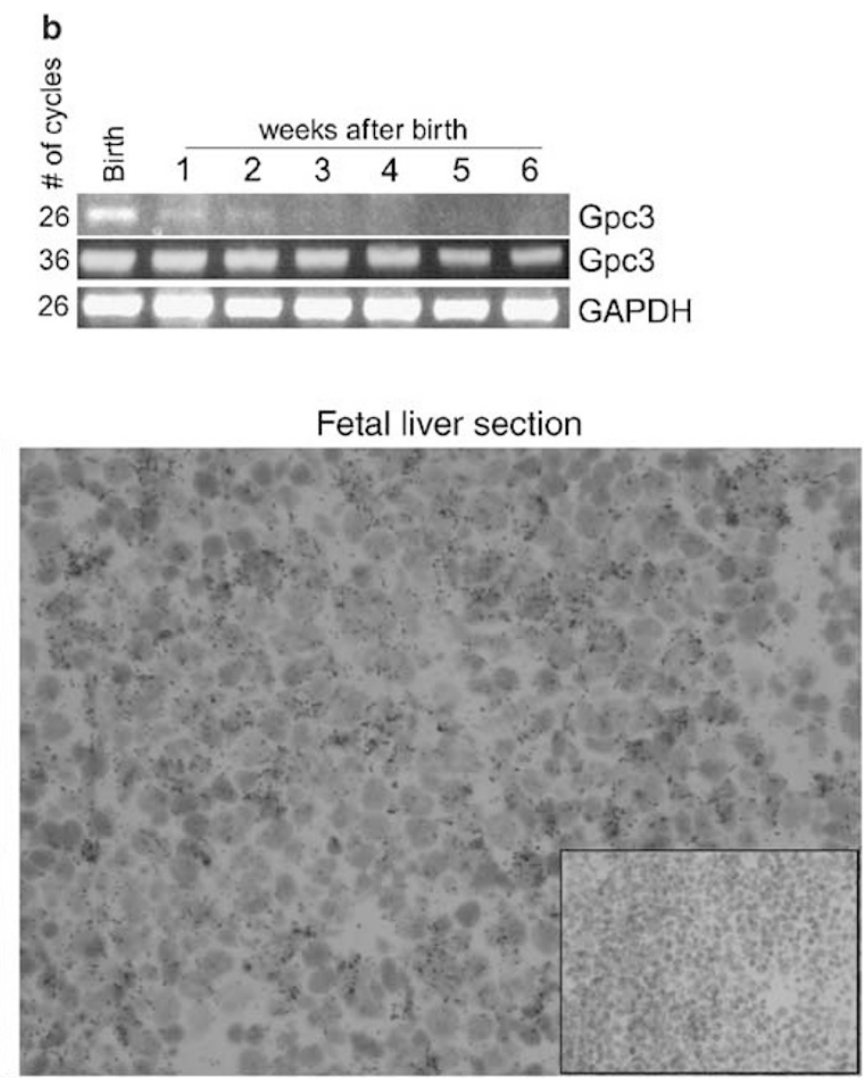

Figure 1 Expression of Gpc3 mRNA in rat liver during development. (a) Relative Gpc3 mRNA abundance in fetal liver at embryonic days (E) 13, 14, 15, 17, 18, at birth and 7 days (7D) after birth. Data were average from three independent cDNA microarray experiments. (b) Decline of Gpc3 expression 3 weeks after birth assessed by semiquantitative RT-PCR and agarose gel electrophoresis. Presented are the generated products after 26 and 36 cycles. GAPDH expression was used as an internal control. (c) Dual ISH for simultaneous detection of Gpc3 (grains) and AFP (brown color) (mRNA) in isolated fetal liver cells (original magnification $\times 400$ ) and fetal liver section (original magnification $\times 200$ ). Insets: ISH with sense (Gpc3 and AFP) riboprobes as negative controls. Same magnification as in positive samples. Nuclei were counterstained with hematoxylin. 


\section{Total Protein Isolation and Western Blots}

Frozen liver tissue from normal adult and 2-AAF/ $\mathrm{PH}$ livers at 2, 10, 16, 20 and 30 days after $\mathrm{PH}$ was homogenized in RIPA buffer $(50 \mathrm{mM}$ Tris-HCl, $\mathrm{pH}$ 7.4, $150 \mathrm{mM} \mathrm{NaCl}, 1 \%$ Nonidet P-40, $1 \mathrm{mM}$ EDTA, $1 \%$ sodium deoxycholate, $0.1 \%$ SDS) supplemented with proteinase inhibitors, Complete Mini (Roche Applied Science). The homogenate was centrifuged for $10 \mathrm{~min}$, at $10000 \mathrm{~g}$ in the cold. The supernatant was transferred to a new tube and protein content measured with BCA reagent (Pierce Biotechnology, Inc., Rockford, IL, USA) for $30 \mathrm{~min}$ at $60^{\circ} \mathrm{C}$. One hundred $\mu \mathrm{g}$ of total protein was boiled for $5 \mathrm{~min}$ with equal volume of $2 \times$ loading buffer (Bio-Rad, Hercules, CA, USA) and applied on $7.5 \%$ SDS polyacrylamide gel. Fractionated proteins were transferred to PVDF membrane (Bio-Rad) by semidry transfer. The membrane was blocked in 5\% nonfat milk in washing buffer (100 mM Tris-HCl, $\mathrm{pH} \mathrm{7.4,}$ $150 \mathrm{mM} \mathrm{NaCl}, 0.1 \%$ Tween-20) for $1 \mathrm{~h}$ at RT. Overnight incubation with primary antibodies was followed by three washes with washing buffer and incubation with secondary POD conjugated antibody. POD activity was developed with Super Signal West Femto Maximum Sensitive Substrate (Pierce Biotechnology, Inc.). The chemiluminescence was visualized on Fuji Super RX films.

\section{Results}

\section{Expression of Gpc3 in Fetal Hepatoblasts}

Using mouse cDNA microarrays we identified Gpc3 as a differentially expressed gene in fetal hepatoblasts. The expression pattern of this gene in rat fetal hepatoblasts was studied at embryonic days 13, 14, 15, 17, 18, newborn and 7 day after birth. RNA was isolated from fetal hepatoblasts and used as a tester RNA, vs newborn RNA, which served as a reference. As presented in Figure 1a, higher expression of Gpc3 was observed early in fetal life (embryonic days 1314), and then it gradually decreased. To determine how long after birth Gpc3 is expressed in the liver, we carried out another experiment, in which we followed its expression in the course of several weeks after birth using RT-PCR. As shown in Figure $1 \mathrm{~b}$ the expression of Gpc3 declined gradually and was not observed in the liver of 3-week-old animal after 26 cycles of PCR. However, expression of Gpc3 was detectable in the liver of adult animal after 36 cycles (see Figure 1b). As fetal liver is rich in hematopoietic cells, to distinguish these cells from hepatoblasts we applied dual ISH on fetal liver sections and isolated fetal liver cells. Gpc3 mRNA was detected with radioactive $\left({ }^{35} \mathrm{~S}\right)$ riboprobe and AFP was detected with digoxigenin labeled riboprobe. As shown in Figure 1c, the expression of Gpc3 is restricted only to fetal hepatoblasts $\left({ }^{35} \mathrm{~S}\right.$ radioactive label, grains). Its expression colocalizes with that of AFP (digoxigenin label, brown), which proves that Gpc3 it is not expressed in the hematopoietic cells (these cells do not express AFP). These experiments show that Gpc3 is highly and differentially expressed in fetal hepatoblasts and that its expression is gradually downregulated in adult liver.

\section{Expression of Gpc3 in Hepatic Progenitor/Oval Cells}

RT-PCR analysis of Gpc3 expression

To determine whether Gpc3 is also expressed in the adult hepatic progenitor cells, we studied its
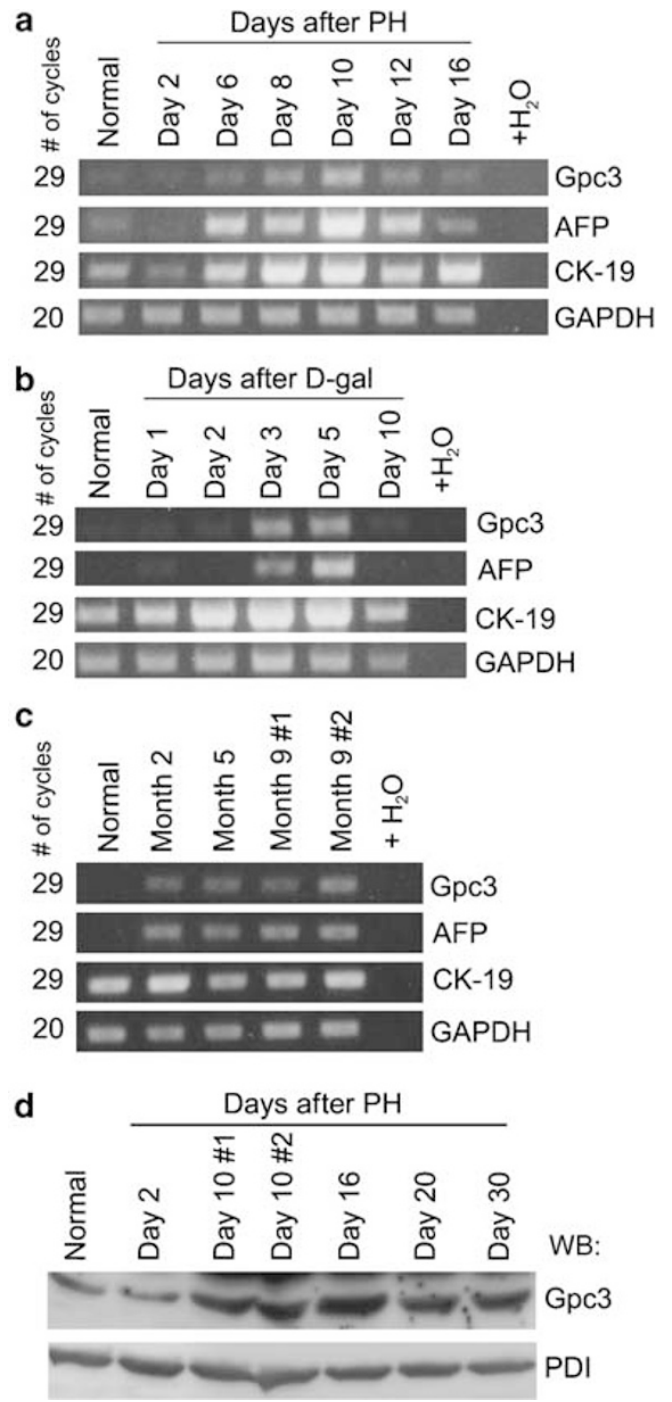

Figure 2 Expression of Gpc3 mRNA in rat liver injury models. Semiquantitative RT-PCR analysis of Gpc3, AFP, CK-19 and GAPDH (internal control) mRNA expression in: (a) 2-AAF/PH; (b) D-gal liver injury models at the indicated time points. (c) Livers of animals subjected to Solt-Farber protocol for inducing hyperplastic liver lesions at indicated time points. Gpc3 expression in the liver of two animals at 9 months (\#1 and \#2) is presented. (d) Western blot analysis of the Gpc3 protein in normal adult and 2-AAF/PH injured livers at indicated days after $\mathrm{PH}$. Gpc3 protein content in the livers of two animals (\#1 and \#2) from the $2-\mathrm{AAF} / \mathrm{PH}$ model at day 10 is represented. The same membrane was reprobed with anti-PDI antibody used as internal loading control. 

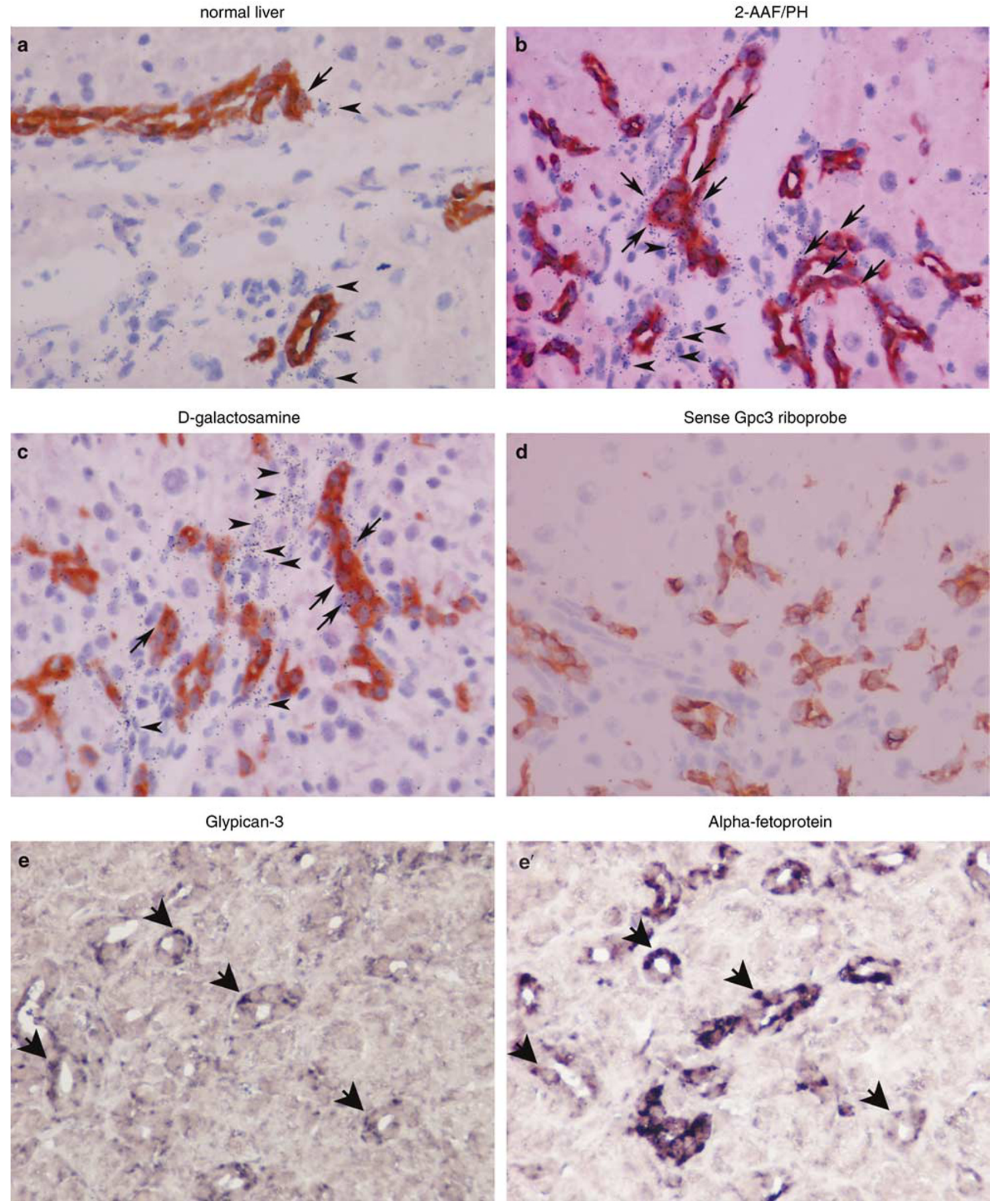

Figure 3 ISH analysis of Gpc3 mRNA in normal liver and in the liver with activation of progenitor/oval cells. IHC/ISH for simultaneous detection of CK-19 (brown color) and Gpc3 mRNA (grains): (a) normal, (b) 2-AAF/PH at day 10 after surgery and (c) D-gal at day 5 treated animals. Arrows: double labeled cells expressing both CK-19 and Gpc3; arrowheads: only Gpc3 positive cells. (d) hybridization with sense Gpc3 riboprobe (negative control). The tissues were stained with H\&E; original magnification $\times 400$. (e and $\mathbf{e}^{\prime}$ ), ISH for detection of Gpc3 mRNA and AFP mRNA on serial tissue sections from 2-AAF/PH animal (day 10): (e) Gpc3 and (é⿱一土 $)$ AFP mRNA detection. Short arrows denote the identical double positive cells in both sections. Original magnification $\times 400$. 
expression in models of oval cells activation and proliferation: in the liver of 2-AAF-treated animals at different time points after $\mathrm{PH}$ and in D-gal-treated animals at 1 through 10 days after the injection. Total RNA was extracted from the livers of these animals and subjected to RT-PCR analysis.

In both models, expression of Gpc3 was markedly increased. Maximum expression was observed on day 10 in the 2-AAF/PH model, coinciding with the highest expression of CK-19 and AFP (CK-19 and AFP are two well-known markers of oval cells, see Fausto and Campbell, ${ }^{1}$ Dabeva and Shafritz, ${ }^{2}$ Grisham and Thorgeirsson, ${ }^{3}$ Alison et al, ${ }^{4}$ Sell ${ }^{5}$ and Roskams et $\mathrm{al}^{6}$ ) (Figure 2a). At 16 days after PH, the level of Gpc3 already declined and 20 days after $\mathrm{PH}$ the expression reached normal levels. The expression of Gpc3 was also highly increased in the D-gal model after day 3 , reaching maximum on day 5 , which was also the maximum for AFP expression (Figure 2b).

To determine the protein level of Gpc3 we carried out Western blot analysis with total liver lysates from adult normal and 2-AAF/PH injured livers on day 2, 10, 16, 20 and 30 after PH (Figure 2d). Gpc3 protein was detectable in normal liver and at day 2 after PH (100 $\mu$ g of protein loaded). At day 10 and 16 Gpc3 gene products reached its maximum and then slowly decreased at day 20 and 30 , but remained higher than the normal liver. These results show that both Gpc3 mRNA and protein are upregulated in the two liver injury models and when the level of mRNA returns to normal, the expression of the protein is still upregulated, most probably due to the longer half-life of this protein.

\section{ISH analysis of Gpc3 expression}

The expression of Gpc3 in hepatic progenitor/oval cells was further studied by combined dual ISH/IHC analysis on liver sections of normal and 2-AAF/PH and D-gal-treated rats, using radioactive labeled Gpc3 antisense probe and CK-19 antibody. In normal liver, few Gpc3 positive cells colocalized with CK-19 positive cholangiocytes of the bile ducts (Figure 3a) (arrow) and few others were CK-19 negative showing periductular localization (arrowhead). In the two liver injury models, the labeling with CK-19 anti- body detected the oval cells forming the typical branching duct-like structures, expanding from the periportal region and invading into the parenchyma (brown color) (Figure $3 \mathrm{~b}$ and c). The expression of Gpc3 (grains, arrows) colocalized with the expression of CK-19 in oval cells; however, some other periductular cells that were CK-19 negative were also Gpc3 positive (grains, arrowheads). These data clearly show that Gpc3 is expressed in two subpopulations of liver oval/progenitor cells, one expressing and the other not expressing CK-19. To determine whether the second population of Gpc3 positive and CK-19 negative cells could be cells already committed to the hepatocytic lineage we performed ISH on serial sections, using digoxigenin labeled Gpc3 and AFP riboprobe, respectively, and detecting the hybrid with antidigoxigenin-AP and visualizing AP with BCIP/NBT as substrate (purple color). The results presented in Figure $3 \mathrm{e}$ and $\mathrm{e}^{\prime}$ demonstrate that progenitor/oval cells coexpress Gpc3 and AFP and that the signals from both genes overlapped in the two sections. The presented above data show that in normal liver Gpc3 is expressed at low level in cholangiocytes and in some periductular cells and that Gpc3 expression is highly induced in activated liver progenitor/oval cells.

\section{IF analysis of Gpc3 expression}

The cellular localization of Gpc3 in normal and 2-AAF-treated animals was further studied with double IF microscopy. Gpc3 was detected with antihuman Gpc3 antibody and visualized with Cy2. Oval cells were detected with CK-19 or OV6 monoclonal antibodies against these CKs and visualized with Cy3. In preliminary experiments, we found that Gpc3 antibody also crossreacts with endothelial cells of blood vessel and sinusoids. Blocking with protein lysates from normal liver eliminates this binding (data not shown). In normal rat liver Gpc3 labeling clearly delineates the smallest CK-19 biliary ductules (Figure 4a). Interestingly, this surface protein either encircles entirely the small ductules at the side of the basement membrane (arrows) or forms open circles (small arrows). Few single cells are also Gpc3 positive but CK-19

Figure $4 \mathrm{IF}$ analysis of the expression of Gpc3 in normal liver and in the liver with activation of progenitor/oval cells. Double IF labeling with anti-human Gpc3 (green) and CK-19 or OV6 (both in red) antibodies of (a) normal and (b) 2-AAF/PH-treated livers at day 10 after the surgery. Nuclei were labeled with DAPI (merged). Arrows-Gpc3 and CK-19/OV6 positive bile ducts or duct-like structures, or individual oval cells in 2-AAF/PH-treated rats. Arrowheads-single Gpc3 positive cells. Small arrows open duct-like structures. Original magnification $\times 200$. (c and d) Double IF labeling with anti-human Gpc3 (green) and anti-bovine glial fibrillary acidic protein (GFAP, red) antibodies of liver sections from (c) normal and (d) 2-AAF/PH-treated livers at day 10 after the surgery. No double positive cells were observed. Nuclei were labeled with DAPI (merged). Original magnification $\times 200$. (e) Double IF labeling with anti-human Gpc3 (green) and anti-human desmin (red) antibodies of liver sections from 2-AAF/PH-treated livers at day 10 after the surgery. No double positive cells were observed. Nuclei were labeled with DAPI (blue). Original magnification $\times 400$. Insets magnified view. Arrows clearly indicate that the two signals do not overlap. (f) Confocal pictures of double IF labeling with anti-human Gpc3 (green) and anti-rat laminin antibodies of liver sections from 2-AAF/PH-treated livers at day 10 after the surgery. Total overlapping of both signals appears as yellow when merged. Nuclei were labeled with DAPI (blue). Original magnification $\times 630$. Insets: magnified view of a typical duct-like structure. 

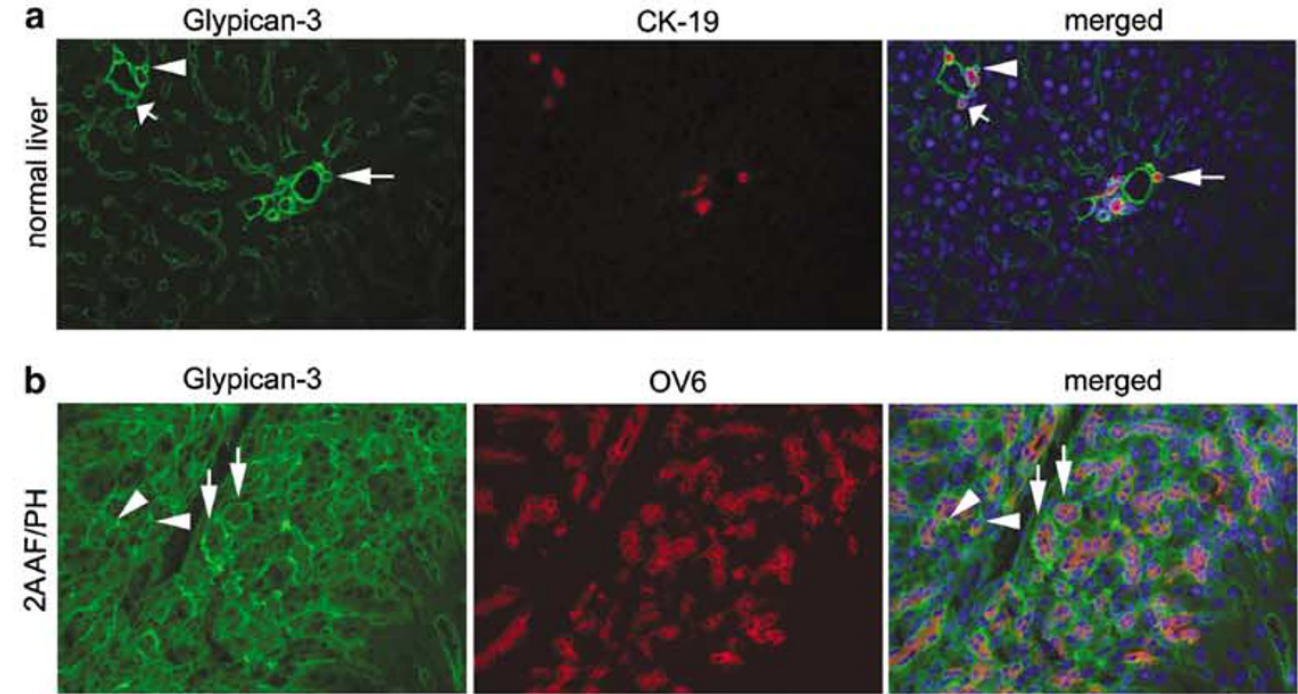

OV6

merged
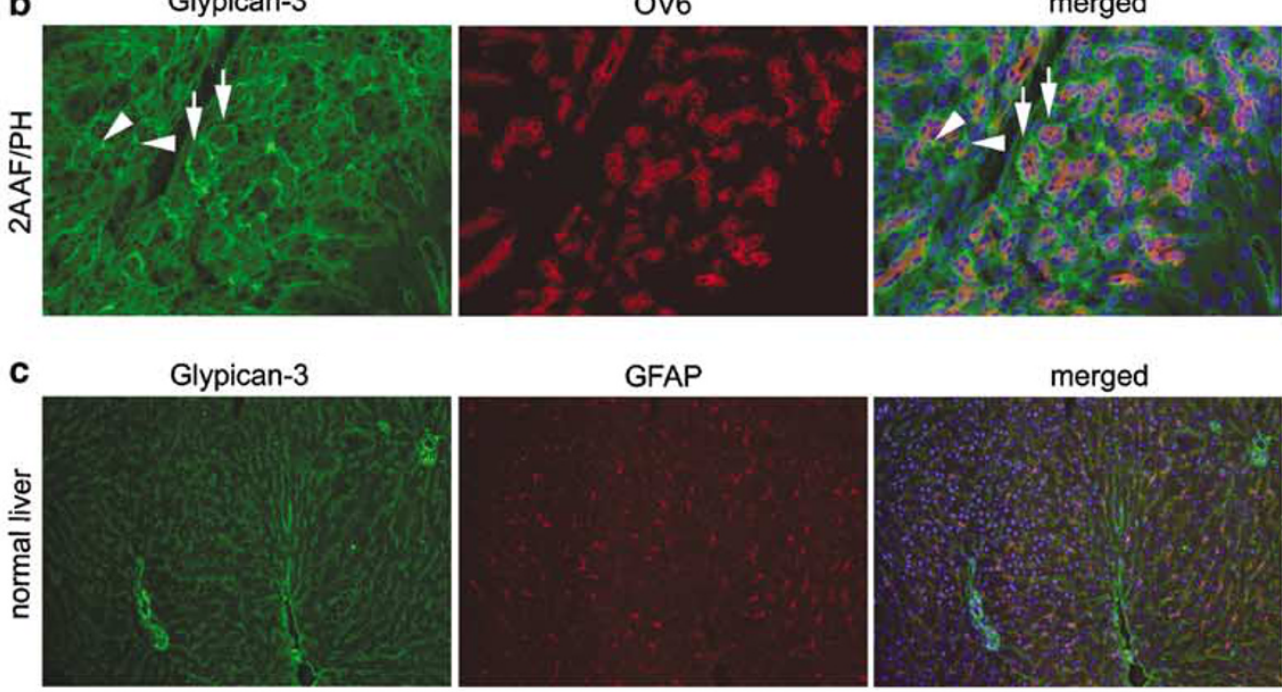

GFAP

merged
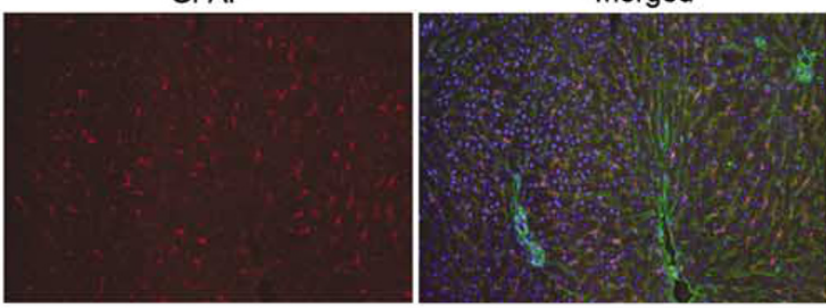

d

Glypican-3

GFAP

merged
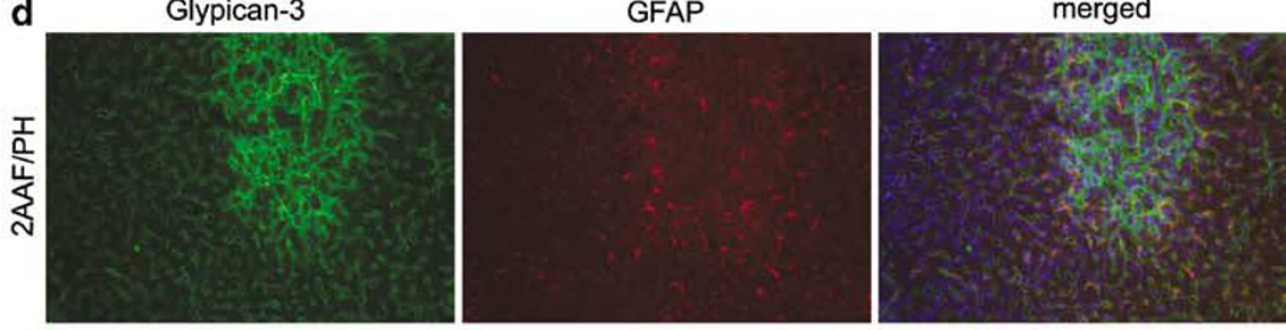

e

Glypican-3

Desmin

merged
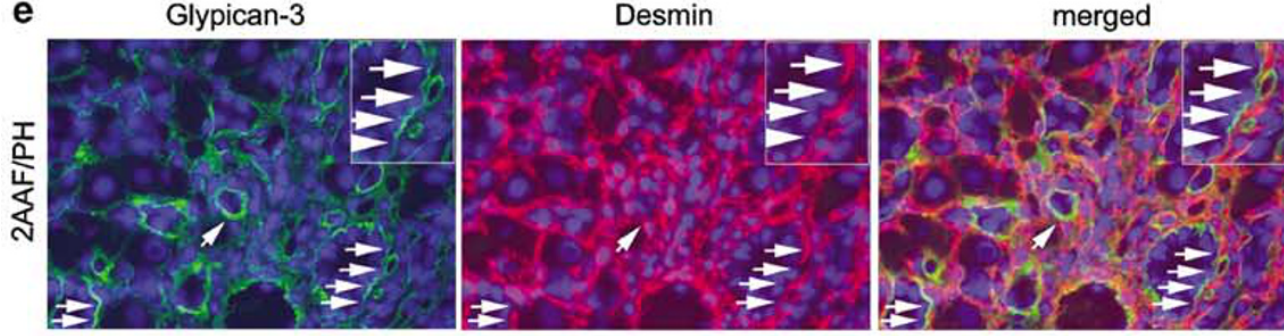

f

Glypican-3

Laminin

merged
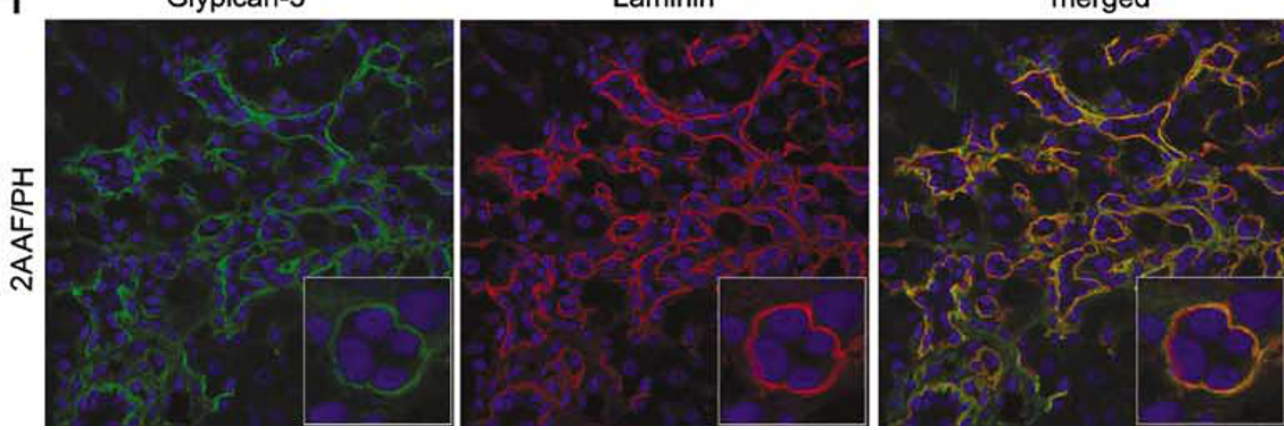
negative (arrowhead). Oval cells of 2-AAF/PHtreated animals are labeled by both OV6 (which detects common epitope in CK-14 and $-19^{32}$ ), and Gpc3. While OV6 antibody labels the duct-like lumen (apical surface of the epithelial cells), Gpc3 antibody labels the basal surface, delineating the basal lamina of the pseudoducts (Figure 4b, arrows). In addition, single Gpc3 and OV6 positive cells outside the biliary ductules are also present, as well as Gpc3 positive cells that do not express OV6 (Figure 4b, arrowheads).

To prove further the localization of Gpc3 on the basal lamina we carried out colabeling experiments of Gpc3 and laminin. As it is shown in Figure $4 \mathrm{f}$ the signals from both proteins colocalize on the basal membrane.

Upon activation, oval cells proliferate in close proximity to stellate cells. ${ }^{33,34}$ To determine whether Gpc3 is expressed in oval cells and not in stellate cells, we performed double IF microscopy experiment using Gpc3 antibody (green color) and GFAP antibody (a marker for stellate cells, ${ }^{35,36}$ red color) or desmin antibody (a marker for activated stellate cells, ${ }^{35,36}$ red color). GAFP positive stellate cells are uniformly distributed throughout normal liver (Figure 4c) but in the 2-AAF/PH model the GAFP marker seems less represented (Figure 4d). In contrast, the desmin positive activated stellate cells surround proliferating oval cells and are densely packed around them. However, there is no overlap of the two labels, showing that Gpc3 is indeed expressed only in the progenitor cells and not in the stellate cells (Figure 4e, arrows). Our results demonstrate again the intimate contact between proliferating oval cells and activated stellate cells. ${ }^{37,38}$ Our results show further that this heparan sulfate is located in the basal lamina of expanding oval cells, while desmin positive cells are outside surrounding the pseudoduct structures.

\section{Expression of Gpc3 in isolated cells}

To confirm that Gpc3 is expressed in oval cells we tried to isolate the cells using Gpc3 antibody. However, during the collagenase/pronase digestion, required for isolation of NPC, the protein was removed from the cell surface. Alternatively, we isolated oval cells using the procedure described by Petersen et $a l^{39}$ and isolated cells that were Thy1 positive and CD45 negative. The expression pattern of these cells is presented in Figure 5a. These oval cells express AFP, CK-19 and Gpc3, but not CD45.

Pure desmin positive cells in the context of oval cells expansion could not be isolated by density gradient centrifugation as these 'activated' stellate cells sediment with the oval cells. To overcome this problem, we used antibodies against stellate cells specific surface marker PDGFR- $\beta .^{40,41}$ The expression profile of the isolated stellate cells is presented in Figure 5b. These cells are positive for desmin, but negative for AFP, CK-19 and Gpc3. These results

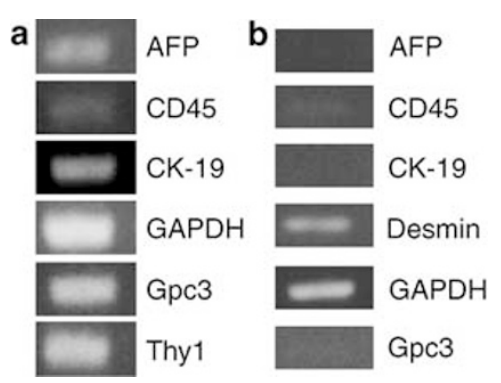

Figure 5 mRNA expression analysis of isolated Thy1 positive progenitor and PDGFR- $\beta$ positive stellate cells. Thy1 ${ }^{+}$cells were isolated from 2-AAF/PH liver at day 10 after surgery and PDGFR$\beta^{+}$cells were isolated from D-gal-treated liver. (a) RT-PCR analysis of AFP, CD45, CK-19, GAPDH, Gpc3 and Thy1 mRNA expression in FACS sorted Thy1 positive/CD45 negative progenitor cells from 2-AAF/PH liver. (b) RT-PCR analysis of AFP, CD45, CK-19, desmin, GAPDH, and Gpc3 mRNA expression in PDGFR- $\beta$ positive stellate cells isolated with microbeads from D-gal-treated liver.

clearly show that Gpc3 is expressed in Thy1 positive oval cells and not expressed in stellate cells.

\section{Expression of Gpc3 in Liver Lesions Induced by the SFC Protocol}

Treatment of animals with 2-AAF in conjunction with $\mathrm{PH}$ activates $\mathrm{Gpc} 3$ expression in oval cells. After a month the expression of Gpc3 returns to normal. However, when the animals were treated with a single injection of the tumor initiator, diethylnitrosamine, before 2-AAF/PH, the expression of Gpc3 did not subside. Elevated expression was observed in the course of 9 months (Figure 2c). Indeed, double IF analysis for detection of Gpc3 and CK-19 showed persistent $\left(\mathrm{Gpc} 3^{+}, \mathrm{CK}-19^{+}\right)$oval cell clusters after 2 months (Figure 6a). The number of these foci increased over time and 9 months after the beginning of the experiment multiple lesions resembling oval cell duct-like structures or atypical ductular reaction were frequently observed. These atypical ductules express both CK-19 and Gpc3 (Figure 6b), demonstrating the persistent expression of Gpc3 in liver lesions induced by the SFC protocol. Figure 6c represents IHC for CK-19 and H\&E staining of a liver lesion and Figure 6d gives a micrograph of partial large cluster of H\&E staining of the same paraffin embedded tissue.

\section{Expression of Gpc3 in Cell Lines}

Finally, we tested the expression of Gpc3 in an oval cell line established from the liver of Fisher 344 rats on day 5 after injection of D-gal, in a differentiated hepatoma cell line FAO- ${ }^{42}$ and in an epithelial cell line WB-F344 sharing phenotypic properties with oval cells. ${ }^{3,43}$ RNA was isolated and RT-PCR analysis was performed as described in Materials and methods. Figure 7a presents the RT-PCR analysis 
a

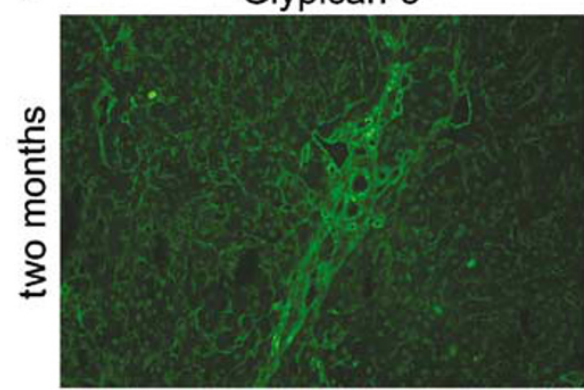

CK-19

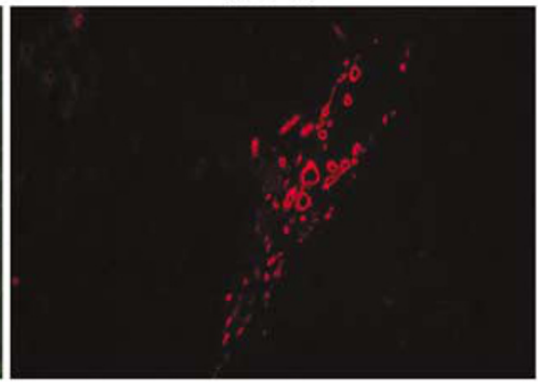

b
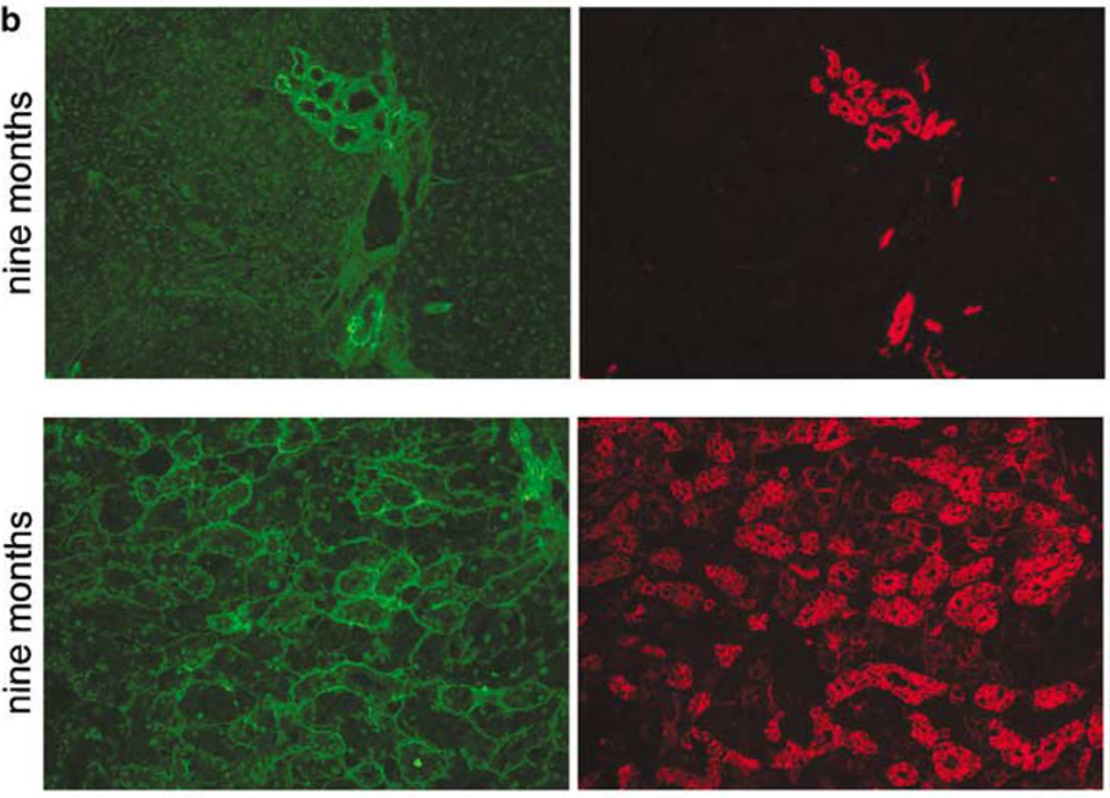

merged
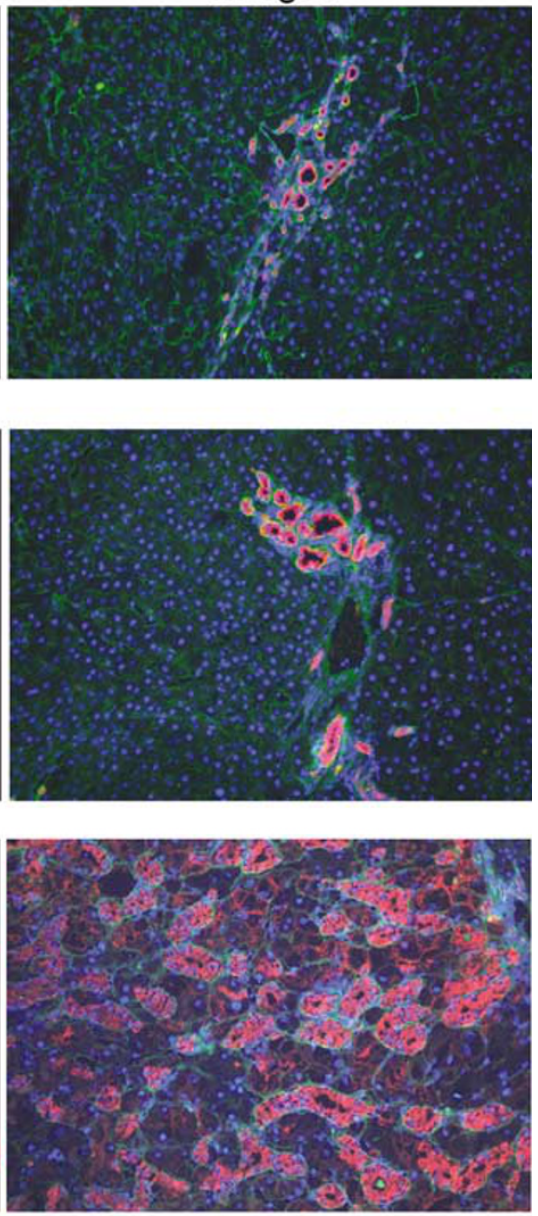
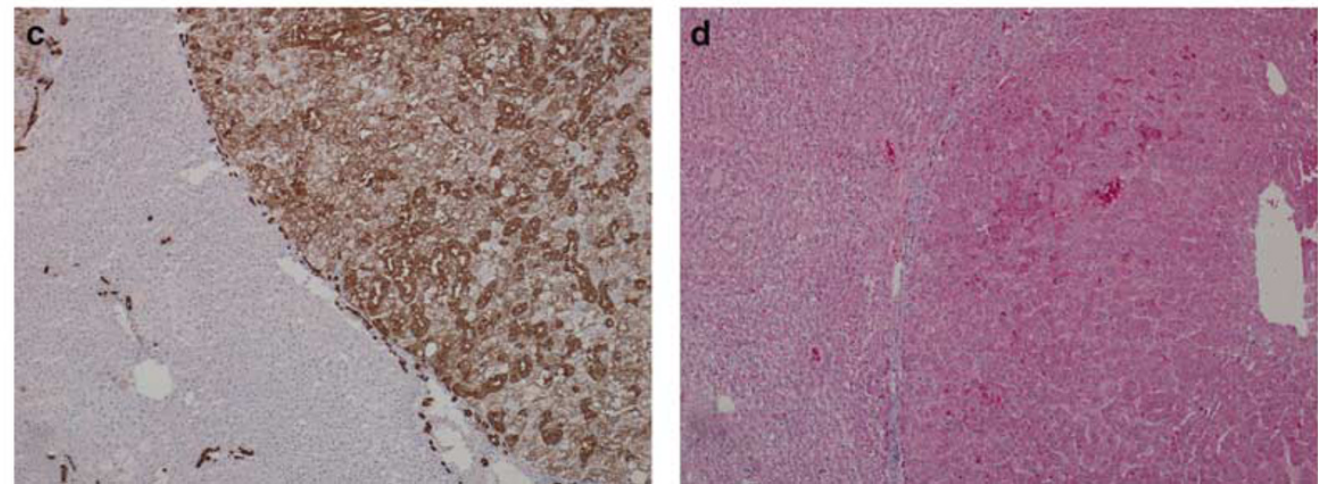

Figure 6 IF analysis of the expression of Gpc3 in SFC model. Double IF labeling with Gpc3 (green) and CK-19 (red) antibodies of liver from rats subjected to Solt-Farber protocol for 2 months (a) and 9 months (b). Multiple lesions resembling duct-like structures or atypical ductular reaction were observed in (b). Original magnification $\times 400$. (c) Neighboring section of the one presented in (b) was stained with CK-19 (brown color), H\&E. (d) Routine H\&E staining of paraffin embedded tissue from the same liver presented in (b and c) showing similar tissue lesions. Original magnification $\times 50$.

of these cell lines. FAO-1 cells do not express Gpc3. Our oval cell line and WB-F344 express Gpc3. In addition, IF analysis of the oval cells with antihuman Gpc3 antibody revealed the surface labeling for Gpc3 (Figure 7b). These results clearly show that oval cells are the source of Gpc3 in the injured liver and that after isolation and propagation the oval cells continue to express Gpc3.

\section{Discussion}

Oval cells express markers specific for biliary epithelial cells, like CK-7, CK-8, CK-18, CK-19, OV6, connexin 43, mouse A6 antigen and others, markers for immature fetal hepatoblasts, like AFP, $\gamma$-glutamyl transpeptidase (GGT), muscle type pyruvate kinase (M2-PK) and markers for hematopoietic 
a

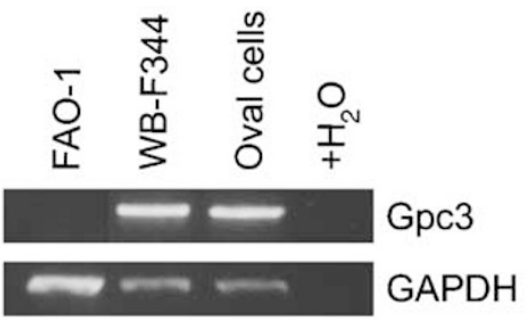

b
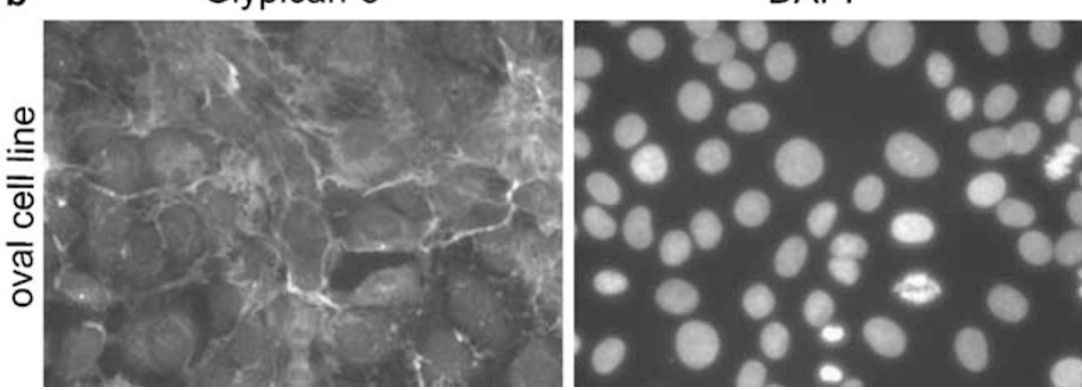

phase contrast

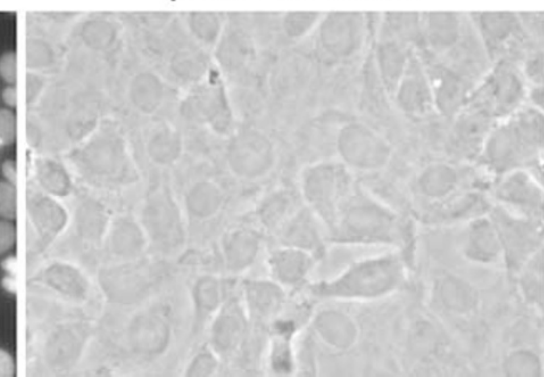

Figure 7 Expression of Gpc3 mRNA in different cell lines and IF analysis. (a) Expression of Gpc3 mRNA was assessed by RT-PCR reaction and agarose gel electrophoresis in FAO-1 differentiated hepatoma, WB-F344 frozen epithelial cell line and oval cell lines. GAPDH was used as internal control. (b) IF labeling with anti-human Gpc3 antibodies. Nuclei were labeled with DAPI. Phase contrast image of the cells is presented. Original magnification $\times 400$.

stem cells, like Thy-1, c-kit, CD34, Sca-1 and others (see Fausto and Campbell, ${ }^{1}$ Dabeva and Shafritz, ${ }^{2}$ Grisham and Thorgeirsson ${ }^{3}$ and Alison et $a l^{4}$ and references therein). Few markers specific for oval cells, not expressed by other liver cell types were reported: chromogranin $\mathrm{A},{ }^{44}$ and Dlk- $1 .{ }^{45}$

In this work, we show for the first time that in addition to AFP, Gpc3 is another oncofetal protein marker expressed in liver progenitor cells. This result was obtained with two different animal models of activation of progenitor/oval cells: 2$\mathrm{AAF} / \mathrm{PH}$ and D-gal; and by applying three independent cell and molecular analyses: RT-PCR analysis, combined ISH, IHC and IF analyses and FACS analysis of Thy1 positive oval cells. Gpc3 is expressed in morphologically distinguishable oval cell structures forming branching duct-like structures emanating from the portal region of the liver acinus. These cells coexpress the oval cell markers CK-19 and OV6. Our IF microscopy analyses show that Gpc3 is a component of the basal membrane of the oval cell pseudoducts, positioned between oval cells and stellate cells and colocalizes with laminin that delineates the basal membrane. However, Gpc3 is not expressed in the stellate cells judged from the lack of its mRNA in isolated stellate cells and from the double IF analysis for desmin and Gpc3, showing that the two proteins are not localized in the same cellular/extracellular compartment. For this reason it is likely that Gpc3 serves as receptor for signal molecules secreted by the stellate cells. In addition, Gpc3 is expressed in a second population of cells that are CK-19 negative and show periductular localization. During differentiation hepatic progenitor cells lose some of their markers and acquire others. ${ }^{46-48}$ As Gpc3 is coexpressed with AFP, the hallmark of liver progenitor cells, we assume that the second population of periductular cells is hepatocytic progenitors. Given that Gpc3 is expressed in all hepatoblasts in fetal liver and in AFP positive and/or CK-19 positive cells of the injured livers with activation of oval cell compartment, we believe that Gpc3 is a marker for all hepatic progenitor cells.

In normal liver, few nonparenchymal cells reveal expression of Gpc3. These cells are part of small biliary epithelial structures or are single CK-19 positive cells. Other CK-19 negative cells are located in the periportal region. It is commonly believed that liver progenitor cells originate from the canals of Hering, lined by both hepatocytes and biliary ductular epithelial cells. ${ }^{1-4}$ In a few studies, when allyl alcohol was used to cause liver injuries, small intra portal 'stem' cells were reported to proliferate in response to the injury. ${ }^{49,50}$ Our findings show that Gpc3 is expressed in both types of cells: those located in the canals of Hering and also in cells in the periportal region that could represent the second population of progenitor cells expressing AFP and Gpc3 but not CK-19.

The expression of Gpc3 is not downregulated in animals subjected to initiation and tumor promotion, according to SFC protocol. In this protocol, proliferation of oval cells is not inhibited by 2-AAF. As a consequence of this, the initiated oval cells proliferate in response to $\mathrm{PH}$ forming clusters of duct-like structures that eventually enlarge into atypical hyperplastic ductular reaction. Gpc3 expression persists in the duct-like oval cell structures and in the preneoplastic lesions, expressing both 
CK-19 and Gpc3. The fact that oval cells continuously express Gpc3 during promotion, while changing their morphological appearance, strongly supports the idea that liver progenitor/oval cells are the origin of hepatocellular carcinoma in this model.

The exact function and mechanism of action of Gpc3 is not known. It was reported that this surface molecule modulates growth factor signaling (fibroblast growth factor-2, BMP-4, BMP-7) ${ }^{14,16,18}$ and both canonical and noncanonical Wnt signaling. ${ }^{17,51}$ Interestingly, the expression of Gpc3 is turned on in carcinomas originating from tissues that normally do no express it, that is, hepatocellular carcinoma and melanoma.$^{52}$ In contrast, its expression is turned down in tumors originating from tissues that normally express it, that is, mammary gland ${ }^{53}$ and lung. ${ }^{54}$ Here, we showed that oval cells coexpress AFP/CK-19 and Gpc3. It is possible that Gpc3 terminates their growth and induces their differentiation. Such a mechanism is supported by the fact that in SGBS of Gpc3-deficient mouse model fetal cells cannot stop their proliferation and overgrowth was observed..$^{11-15}$

Our efforts are currently aimed at elucidation the function of Gpc3 in liver progenitor cells. Once the biological function of this proteoglycan in hepatic tissue is elucidated, it may be possible to use this master switch of proliferation/apoptosis for the benefits of the hepatic cells in disease.

\section{Acknowledgements}

We thank Dr DA Shafritz for critical comments and suggestions, Dr N Fausto for pBAF plasmid, Dr S Sell and Dr R Stockert for OV6 antibody and protein disulfide isomerase antibody, respectively, Dr D Neufeld for liver perfusion, W King for sorting the cells and Ms Ethel Hurston for excellent technical assistance. This work was supported by National Institute of Health Grant R01 DK59321 (to MDD).

\section{References}

1 Fausto N, Campbell JS. The role of hepatocytes and oval cells in liver regeneration and repopulation. Mech Dev 2003;120:117-130.

2 Dabeva MD, Shafritz DA. Hepatic stem cells and liver repopulation. Semin Liver Dis 2003;23:349-362.

3 Grisham JW, Thorgeirsson SS. Liver stem cells. In: Potten CS (ed). Stem Cells. Academic Press Ltd: New York, 1997, pp 233-282.

4 Alison MR, Vig P, Russo F, et al. Hepatic stem cells: from inside and outside the liver? Cell Prolif 2004;37:1-21.

5 Sell S. Comparison of liver progenitor cells in human atypical ductular reactions with those seen in experimental models of liver injury. Hepatology 1998;27: 317-331.

6 Roskams TA, Libbrecht L, Desmet VJ. Progenitor cells in diseased human liver. Semin Liver Dis 2003;23: 385-396.
7 Bernfield M, Gotte M, Park PW, et al. Functions of cell surface heparan sulfate proteoglycans. Annu Rev Biochem 1999;68:729-777.

8 Filmus J, Selleck SB. Glypicans: proteoglycans with a surprise. J Clin Invest 2001;108:497-501.

9 Watanabe K, Yamada H, Yamaguchi Y. K-glypican: a novel GPI-anchored heparan sulfate proteoglycan that is highly expressed in developing brain and kidney. J Cell Biol 1995;130:1207-1218.

10 Paine-Saunders S, Viviano BL, Saunders S. GPC6, a novel member of the glypican gene family, encodes a product structurally related to GPC4 and is colocalized with GPC5 on human chromosome 13. Genomics 1999; 57:455-458.

11 Shen T, Sonoda G, Hamid J, et al. Mapping of the Simpson-Golabi-Behmel overgrowth syndrome gene (GPC3) to chromosome $\mathrm{X}$ in human and rat by fluorescence in situ hybridization. Mamm Genome 1997;8:72.

12 Pilia G, Hughes-Benzie RM, MacKenzie A, et al. Mutations in GPC3, a glypican gene, cause the Simpson-Golabi-Behmel overgrowth syndrome. Nat Genet 1996;12:241-247.

13 Cano-Gauci DF, Song HH, Yang H, et al. Glypican-3deficient mice exhibit developmental overgrowth and some of the abnormalities typical of Simpson-GolabiBehmel syndrome. J Cell Biol 1999;146:255-264.

14 Paine-Saunders S, Viviano BL, Zupicich J, et al. Glypican-3 controls cellular responses to Bmp4 in limb patterning and skeletal development. Dev Biol 2000;225:179-187.

15 Pellegrini M, Pilia G, Pantano S, et al. Gpc3 expression correlates with the phenotype of the Simpson-GolabiBehmel syndrome. Dev Dyn 1998;213:431-439.

16 Grisaru S, Cano-Gauci D, Tee J, et al. Glypican-3 modulates BMP- and FGF-mediated effects during renal branching morphogenesis. Dev Biol 2001;231: $31-46$.

17 De Cat B, Muyldermans SY, Coomans C, et al. Processing by proprotein convertases is required for glypican-3 modulation of cell survival, Wnt signaling, and gastrulation movements. J Cell Biol 2003;163: 625-635.

18 Hartwig S, Hu MC, Cella C, et al. Glypican-3 modulates inhibitory Bmp2-Smad signaling to control renal development in vivo. Mech Dev 2005;122:928-938.

19 Midorikawa Y, Ishikawa S, Iwanari H, et al. Glypican3 , overexpressed in hepatocellular carcinoma, modulates FGF2 and BMP-7 signaling. Int J Cancer 2003;103: $455-465$.

20 Sung YK, Hwang SY, Park MK, et al. Glypican-3 is overexpressed in human hepatocellular carcinoma. Cancer Sci 2003;94:259-262.

21 Nakatsura T, Yoshitake Y, Senju S, et al. Glypican-3, overexpressed specifically in human hepatocellular carcinoma, is a novel tumor marker. Biochem Biophys Res Commun 2003;306:16-25.

22 Capurro M, Wanless IR, Sherman M, et al. Glypican-3: a novel serum and histochemical marker for hepatocellular carcinoma. Gastroenterology 2003;125:89-97.

23 Hippo Y, Watanabe K, Watanabe A, et al. Identification of soluble NH2-terminal fragment of glypican-3 as a serological marker for early-stage hepatocellular carcinoma. Cancer Res 2004;64:2418-2423.

24 Yamauchi N, Watanabe A, Hishinuma $\mathrm{M}$, et al. The glypican 3 oncofetal protein is a promising diagnostic marker for hepatocellular carcinoma. Mod Pathol 2005;12:1591-1598. 
25 Filmus J, Capurro M. Glypican-3 and alphafetoprotein as diagnostic tests for hepatocellular carcinoma. Mol Diagn 2004;8:207-212.

26 Grozdanov PN, Yovchev MI, Dabeva MD. Glypican-3, a marker of liver stem progenitor cells. ISSCR 3rd Annual Meeting. San Francisco, 2005, p 66.

27 Dabeva MD, Laconi E, Oren R, et al. Liver regeneration and $\alpha$-fetoprotein mRNA expression in the retrorsine model for hepatocyte transplantation. Cancer Res 1998;58:5825-5834.

28 Menthena A, Deb N, Oertel M, et al. Bone marrow progenitors are not the source of expanding oval cells in injured liver. Stem Cells 2004;22:1049-1061.

29 Solt DB, Medline A, Farber E. Rapid emergence of carcinogen induced hyperplastic lesions in a new model for sequential analysis of liver carcinogenesis. Am J Pathol 1977;88:595-610.

30 Petkov PM, Zavadil J, Goetz D, et al. Gene expression pattern in hepatic stem/progenitor cells during rat fetal development using cDNA microarrays. Hepatology 2004;39:617-627.

31 Dabeva, MD Hwang S-G, Vasa SRG, et al. Differentiation of pancreatic epithelial progenitor cells into hepatocytes following transplantation into rat liver. Proc Natl Acad Sci USA 1997;94:7356-7361.

32 Bisgaard HC, Parmelee DC, Dunsford HA, et al. Keratin 14 protein in cultured nonparenchymal rat hepatic epithelial cells: characterization of keratin 14 and keratin 19 as antigens for the commonly used mouse monoclonal antibody OV-6. Mol Carcinog 1993;7:60-66.

33 Evarts RP, Hu Z, Fujio K, et al. Activation of hepatic stem cell compartment in the rat: role of transforming growth factor alpha, hepatocyte growth factor, and acidic fibroblast growth factor in early proliferation. Cell Growth Differ 1993;4:555-561.

34 Yin L, Lynch D, Ilic Z, et al. Proliferation and differentiation of ductular progenitor cells and littoral cells during the regeneration of the rat liver to CCl4/ 2-AAF injury. Histol Histopathol 2002;17:65-81.

35 Niki T, De Bleser PJ, Xu G, et al. Comparison of glial fibrillary acidic protein and desmin staining in normal and CCl4-induced fibrotic rat livers. Hepatology 1996;23:1538-1545.

36 Knittel T, Kobold D, Piscaglia F, et al. Localization of liver myofibroblasts and hepatic stellate cells in normal and diseased rat livers: distinct roles of (myo-) fibroblast subpopulations in hepatic tissue repair. Histochem Cell Biol 1999;112:387-401.

37 Paku S, Schnur J, Nagy P, et al. Origin and structural evolution of the early proliferating oval cells in rat liver. Am J Pathol 2001;158:1313-1323.

38 Oben JA, Diehl AM. Sympathetic nervous system regulation of liver repair. Anat Rec A Discov Mol Cell Evol Biol 2004;280:874-883.

39 Petersen BE, Goff JP, Greenberger JS, et al. Hepatic oval cells express the hematopoietic stem cell marker Thy-1 in the rat. Hepatology 1998;27:433-445.
40 Wong L, Yamasaki G, Johnson RJ, et al. Induction of beta-platelet-derived growth factor receptor in rat hepatic lipocytes during cellular activation in vivo and in culture. J Clin Invest 1994;94:1563-1569.

41 Breitkopf K, Roeyen C, Sawitza I, et al. Expression patterns of PDGF-A, -B, -C and -D and the PDGFreceptors alpha and beta in activated rat hepatic stellate cells (HSC). Cytokine 2005;31:349-357.

42 Deschatrette J, Weiss MC. Characterization of differentiated and dedifferentiated clones from a rat hepatoma. Biochimie 1974;56:1603-1611.

43 Tsao MS, Smith JD, Nelson KG, et al. A diploid epithelial cell line from normal adult rat liver with phenotypic properties of 'oval' cells. Exp Cell Res 1984;154:38-52.

44 Roskams TA, Libbrecht L, Desmet VJ. Progenitor cells in diseased human liver. Semin Liver Dis 2003;23: 385-396.

45 Santoni-Rugiu E, Jelnes $\mathrm{P}$, Thorgeirsson SS, et al. Progenitor cells in liver regeneration: molecular responses controlling their activation and expansion. APMIS 2005;113:876-902.

46 Hixson DC, Allison JP. Monoclonal antibodies recognizing oval cells induced in the liver of rats by N-2fluorenylacetamide or ethionine in a choline-deficient diet. Cancer Res 1985;45:3750-3760.

47 Evarts RP, Nagy P, Nakatsukasa $\mathrm{H}$, et al. In vivo differentiation of rat liver oval cells into hepatocytes. Cancer Res 1989;49:1541-1547.

48 Roskams T, Vos RD, Eyken PV, et al. Hepatic OV-6 expression in human liver disease and rat experiments: evidence for hepatic progenitor cells in man. J Hepatology 1998;29:455-463.

49 Yavorkovsky L, Lai E, Ilic Z, et al. Participation of small intraportal stem cells in the restitutive response of the liver to periportal necrosis induced by allyl alcohol. Hepatology 1995;21:1702-1712.

50 Yin L, Lynch D, Sell S. Participation of different cell types in the restitutive response of rat liver to periportal injury induced by allyl alcohol. J Hepatology 1999;31:497-507.

51 Capurro MI, Xiang YY, Lobe C, et al. Glypican-3 promotes the growth of hepatocellular carcinoma by stimulating canonical Wnt signaling. Cancer Res 2005; 65:6245-6254.

52 Ikuta Y, Nakatsura T, Kageshita T, et al. Highly sensitive detection of melanoma at an early stage based on the increased serum secreted protein acidic and rich in cysteine and glypican-3 levels. Clin Cancer Res 2005;11:8079-8088.

53 Peters MG, Farias E, Colombo L, et al. Inhibition of invasion and metastasis by glypican-3 in a syngeneic breast cancer model. Breast Cancer Res Treat 2003; 80:221-232.

$54 \mathrm{Kim}$ H, Xu GL, Borczuk AC, et al. The heparan sulfate proteoglycan GPC3 is a potential lung tumor suppressor. Am J Respir Cell Mol Biol 2003;29:694-701. 